\title{
A CASE STUDY OF VO EDUCATION IN COSTA RICA
}

\author{
César Garita \\ Costa Rican Institute of Technology, COSTA RICA \\ cesar@ic-itcr.ac.cr
}

\begin{abstract}
This paper describes the detailed structure of a Virtual Organization (VO) course, currently being taught as part of undergraduate and Master programs in Computer Science at the Costa Rican Institute of Technology. The course focuses on IT issues and concrete applications of the VO paradigm, and follows a combined theoretical/practical approach with research activities as the base of the learning process.
\end{abstract}

\section{INTRODUCTION}

Several courses in the area of Virtual Organizations are currently being taught or organized as part of different study programs at several universities worldwide (Camarinha-Matos, 2003a; Goranson, 2003; Rabelo, 2003). In general, the role of education in this field may be relevant towards the establishment of the common knowledge and terminology required by multidisciplinary teams engaged in the development of reference VO architectures and IT infrastructures. Given the persistent lack of a common understanding of $\mathrm{VO}$ paradigm concepts, carefully designed courses on VO are necessary in order to train people and help them gain the knowledge, skills and attitudes required to effectively participate in large-scale collaborative VO scenarios. Furthermore, considering the inherent cross-border context of real VO scenarios, it is important to discuss and share the educational experiences in $\mathrm{VO}$ gained at various universities around the world. In this direction, this paper describes the organization of a $\mathrm{VO}$ course currently being taught at the Costa Rican Institute of Technology - ITCR (Garita, 2003a).

The structure of the paper is organized in sections as follows. Section 2 provides a brief description of the study program in which the course is offered. Section 3 includes an overall description and main rationale of the course. In Section 4, the global and specific objectives of the course are explained. The actual course contents, schedule and bibliography are detailed in Section 5. Furthermore, the dynamics of the teaching and learning methodology used by the instructor to interact with the students is analyzed in Section 6. Section 7 provides a summary of the practical project assignments that are given to the students in order to apply the 
concepts studied during the lectures. Finally, Section 8 summarizes the main conclusions of the paper.

\section{GENERAL CONTEXT}

The Department of Computer Science at ITCR is roughly organized in two main study programs: the Undergraduate Program and the Master Program. The semester-based undergraduate program has a duration of 4 years and leads to a Bachelor Degree in Computer Science. At this level, there are around 1000 active students at ITCR. After obtaining the Bachelor Degree, students may continue with their studies in the 2-year semester-based Master Program, which leads to a Scientific (M.Sc.) or Profesional (M.P) Master Degree, with specialization options in Computer Science, Information Systems and Computer Networking. At this level there are about 150 registered students.

The VO course described in this paper has actually been offered and given three times during 2003 and 2004 at ITCR. Namely, the course has been given twice as an elective course at the undergraduate level (I Semester 2003 / I Semester 2004); and once as a Research Seminar course at the Master level (II Semester 2003).

The elective course is taken by students in the last year of studies, and has as prerequisite a Software Design course, which implies that they already have a good command of different programming languages, databases, and software development techniques. About 25 students per semester register this course. For this course, a website (in Spanish) was developed (Garita, 2003a), in which students and other interested persons can find, among other points: a general description of the course, project specifications, VO-related links, grades, and a news group. Through the news group, announcements or questions/answers can be posted on-line to obtain feedback from the instructor and other classmates.

At the Masters level, the course is offered as a research seminar during the first year of the study program. The idea of the research seminar is that the students can identify potential subjects that can be further developed during a second (individual) research seminar and graduation thesis. In this way, the research activities carried out by a student on a given subject can be organized as two research seminars and a thesis along three semesters, which allows enough time to achieve significant research results. Students at this level are assumed to have a solid background in Computer Science. Normally, around 10 students register and follow the research seminar on VO.

The main focus of this paper lies on the research seminar course on VO being taught at the Master Program.

\section{COURSE DESCRIPTION}

The concepts of Virtual Enterprises, Virtual Laboratories, and Virtual Communities can be regarded as specific cases of a more generic VO paradigm. Although there is no standard definition, a Virtual Organization can be described as a temporal alliance of organizations that work together in order to share skills, core competencies, and resources in order to better react to business opportunities 
(Camarinha-Matos, 1999d). The VO paradigm represents a growing field of research and development involving different disciplines such as computer science, industrial engineering, sociology, and business administration. Moreover, the number of international VO projects and applications is constantly increasing, in the areas of industrial manufacturing, service provision and scientific research.

Currently, there is an extremely wide variety of IT approaches, tools, components, models and standards that can be applied in the design and implementation of VO support infrastructures (Camarinha-Matos, 1999c; Garita, 2002a). In particular, the following general areas need to be evaluated for their application within a VE infrastructure: distributed/federated information management systems, workflow management techniques, standard information models and protocols (e.g. EDI, STEP), ontology management systems, advanced Web applications technology, secure and reliable communication protocols, highperformance computing environments, distributed object management architectures, and multi-agent systems among others. In addition to the analysis and proper integration of these technological components, general reference architectures and generic tools must be defined and developed in order to support different kinds of collaborative VO scenarios.

During this course, the student will acquire the basic knowledge necessary to understand the underlying technologies and software tools that enable VO platforms in different application domains. To this end, the course will incorporate specific activities regarding the study and analysis of fundamental concepts, current trends, and novel applications within the VO paradigm. The course will follow a combined theoretical/practical approach with a strong orientation towards research as the base of the teaching and learning activities. It is expected that during this course, students will identify and develop potential subjects for their graduation projects.

\section{COURSE OBJECTIVES}

The objectives of the course are divided in general and specific objectives. The main general objectives are:

- In-depth study of the VO paradigm focusing on related information technologies and concrete applications.

- Explore the application of VO concepts within a national context.

- Develop in the student basic skills to carry out applied research and publish the corresponding scientific results.

- Aim at the establishment of a research group on VO at the Computer Science Department of ITCR.

Furthermore, the specific objectives of the course include:

- Analyze general aspects of VO paradigm, including: definitions, reference models, classifications, reference architectures, and life cycles.

- Study key information technologies for the support of VO platforms.

- Study real application cases of platforms, projects, and initiatives on VO at international level.

- Define collaborative scenarios among organizations following the VO paradigm. 
- Identify, characterize and develop basic tools to support VOs.

- Identify and develop possible subjects for graduation projects.

\section{COURSE CONTENTS AND BIBLIOGRAPHY}

Table 1 summarizes the general contents of the course (with associated bibliographic references) and the expected amount of weeks dedicated to each subject. Every week, a 3-hours lecture takes place and students are expected to dedicate 9 more hours of independent study. Furthermore, please notice that the contents of the course can be roughly divided in two main parts of 8 weeks. Thus, the first half of the course provides a common background and terminology for the class, which will serve as the base for further discussions and projects. In this part, a set of specific VO subjects is analyzed including: an introduction to the paradigm, study cases, distributed information management requirements for VOs, coordination issues, and GRID architecture. During the second part, the course is oriented towards special VO topics and projects that are mostly selected, presented, and developed by the students themselves, as explained later in this paper. In general, the contents, readings, and schedule of the course can always be adjusted depending on the interest and skills of the specific group of students.

Please notice that, in accordance to one of the main objectives of the course, the contents focus mostly on IT issues and applications. This decision is grounded on the technical profile of the students and the nature of the study program in which the course is offered. Nevertheless, other important related topics such cultural, socioorganizational and administrative aspects of the VO paradigm are also discussed and analyzed during the lectures.

Table 1. Summary of course contents.

\begin{tabular}{|c|c|c|}
\hline Part & Subject & Weeks \\
\hline \multirow[t]{5}{*}{ I } & $\begin{array}{l}\text { Introduction to VO paradigm (concepts, definitions, reference models, } \\
\text { organizational issues). } \\
\text { (Byrne, 1993; Camarinha-Matos, 1999c; Camarinha-Matos, 1999d; } \\
\text { Chesbrough, 1996; Flaig, 1992) }\end{array}$ & 2 \\
\hline & $\begin{array}{l}\text { Study cases in VO (virtual communities, industrial manufacturing, value- } \\
\text { added service provision, virtual labs). } \\
\text { (Afsarmanesh, 2002; Camarinha-Matos, 2001; Camarinha-Matos, } \\
\text { 1999b; Camarinha-Matos, 2002; Foster, 2002; Foster, 2001; Garita, } \\
\text { 2002b; Garita, 2003b) }\end{array}$ & 3 \\
\hline & $\begin{array}{l}\text { Distributed Information Management in VOs. } \\
* \quad \text { (Garita, 2001; Garita, 2002a; Sheth, 1990) }\end{array}$ & 1 \\
\hline & $\begin{array}{l}\text { Workflow management and coordination within VOs } \\
\& \quad \text { (Camarinha-Matos, 1999e; Osorio, 1999; WFMC, 1994) }\end{array}$ & 1 \\
\hline & $\begin{array}{l}\text { Distributed resource management in VOs (GRID architecture) } \\
\& \quad \text { (Foster, 2002; Foster, 2001; Globus, 2002) }\end{array}$ & 1 \\
\hline II & $\begin{array}{l}\text { Special VO topics (e.g. current challenges and trends, ontology } \\
\text { management, security issues, web services, e-science, agility, etc.) and } \\
\text { presentation of students' projects. } \\
\text { (Camarinha-Matos, 1999a; Camarinha-Matos, 2002; Camarinha- } \\
\text { Matos, 2003b; Goranson, 1999;THINKcreative, 2002;VOmap, 2002) }\end{array}$ & 8 \\
\hline
\end{tabular}


Regarding the bibliography for the course, it is difficult to point out a book comprehensive enough to be used as the base for all the lectures. However, (Camarinha-Matos, 1999b) can be used to cover a good part of the contents. Many other sources are studied during the course or recommended as reference material in order to develop the assigned projects. Other selected readings are used based on the profile and interest of the particular group of students.

\section{TEACHING AND LEARNING METHODOLOGY}

This research seminar provides the student with an opportunity to explore by him/herself (under instructor's guidance) a subject of his/her own interest related to the VO paradigm. The selected subject must contribute to the scientific or technological development of a specific area within this paradigm. The course encompasses activities led by the instructor regarding the introduction of specific subjects (i.e. first part of the course described in previous section), as well as independent activities led by the students to investigate and explore interesting subjects on their own (i.e. second part of the course contents). During each session, specific subjects are analyzed based on papers or other sources that are read in advance by the students. Lectures try to stimulate an active participation of the students in the classroom. In this scenario, the instructor acts as a coordinator that facilitates communication and exchange of ideas among the students, and provides complementary material for the research activities. In general, the course follows a combined theoretical/practical approach to study how the proper integration of different technologies, models and generic components within VO support platforms, can be achieved. Furthermore, small/medium projects are assigned to the students, in order to enable a detailed analysis of a particular subject of interest. These projects are aimed at the development of basic research skills in the students as well as the identification of possible thesis subjects.

In summary, the following specific learning activities are considered during the course:

- Individual reading assignments.

- Presentation and analysis of selected readings (by the instructor).

- Research and development projects (described later in this paper).

- Presentations and discussions of specific topics and project results (by the students).

- Plenary discussions of particular application cases.

\section{PRACTICAL ASSIGNMENTS}

As mentioned previously, several practical assignments or projects are defined through which the students apply and develop the concepts studied during the course. Normally, students work on the projects individually or in pairs. A brief summary of each of the 4 projects assigned during the course is provided below.

- Project 1: Definition of a VE Scenario Case. In this project, the students propose a real-case VE collaborative scenario in a given sector. Namely, the students identify a business opportunity in a given application domain, that can 
be best satisfied by the proper operation of several enterprises acting as a VE. The students then define a realistic collaborative scenario including for instance: general VE goals, VE partner roles and competencies, and the main information/product flows among VE partners. Furthermore, a paper describing all the elements of the VE scenario must be written in compliance with the latest PROVE conference guidelines.

- Project 2 - Description of Research Topic (VO Tool). The objective of this project is to identify, propose and characterize the research topic that each student (or group of students) will further analyze during the rest of the course. The main output of this project is a detailed proposal for a tool (software component) that offers a specific set of functionalities required to support some of the activities involved in a given VO scenario. The target VO tool must be an independent and generic software component, and must explicitly incorporate concepts such as: VO topology, VO partner access rights, VO contracts, etc. Please notice that the VO tool is defined and proposed by the students themselves, and approved by the instructor.

- Project 3 - General Design of Proposed VO Tool. The third project consists in the design of the VO tool that was identified and proposed in the second project. For this project, the students write a technical document including a requirement analysis and general design of the selected tool. The design activities follow UML as software development methodology. The technical document include among others the following points:

- Requirements analysis.

- General system architecture.

- Detailed design including use-case specification and class diagrams.

- Identification of applicable software development standards or tools (e.g. Java, XML).

- Project 4 - Further Design and Prototype Development of VO Tool. In the fourth and last project, the students implement a prototype of the VO support tool, according to the proposal and design submitted in projects 2 and 3 . Basically, Project 4 is a continuation of the work proposed in previous projects. Furthermore, the students write a Technical Report describing the final results of the research work carried out during the entire seminar. The best documents are selected and published as Technical Reports of the Computer Science Department of ITCR. In addition, the results of each project are also discussed during short presentations to the class.

Examples of research projects proposed and developed by students following the described guidelines include for instance:

- An Administration Tool for GRID Security.

- A Workflow Editor Tool.

- A VE Topology Configurator Tool.

- XML-based Federated Export Schema Management.

- A VE Broker in Tourism.

- A VE Broker for service provision in e-Government.

- A Web-based VO Directory. 


\section{CONCLUSIONS}

The presented VO course has been very well accepted by students at both undergraduate and Master levels at ITCR. Consequently, the course is planned to be given again in coming semesters in both programs. Furthermore, as a result of the course activities, invited talks on VO issues have been requested by commercial companies and other universities through contacts established by the students themselves. Regarding future directions, the possibility of offering a "Virtual Course on Virtual Organizations" (using e-learning techniques) can be evaluated. There is also a need to establish a stronger collaboration among universities offering VO courses in different countries. For example, it would be interesting to gather worldwide proposals for projects that may be developed by students in VO courses, as well as a to exchange and share bibliographic references and other course materials among different universities. Finally, it is clear that more textbooks in this area are necessary in order to facilitate $\mathrm{VO}$ educational tasks.

\section{REFERENCES}

1. Afsarmanesh, H., Belleman, R., Belloum, A. S. Z., Benabdelkader, A., van den Brand, J. F. J., Eijkel, G. B., Frenkel, A., Garita, C., Groep, D. L., Heeren, R. M. A., Hendrikse, Z. W., Hertezberger, L. O., Kaandorp, J., Kaletas, E. C., Korkhov, V., Laat, C. T. A. M. d., Sloot, P. M. A., Vasunin, D., Visser, A., and Yakali, H. H. "VLAM-G: A Grid Based Virtual Laboratory." Scientific Programming Journal Special Issue on Grid Computing, 10(2), 173-181, 2002.

2. Byrne, J. A., and Brandt, R. "The Virtual Corporation." in Business Week, 99-103, February, 1993.

3. Camarinha-Matos, L., and Afsarmanesh, H. "Further Developments in Virtual Enterprises." in Infrastructures for Virtual Enterprises - Networking Industrial Enterprises, L. M. Camarinha-Matos and H. Afsarmanesh, eds., Kluwer Academic, 491-496,1999a.

4. Camarinha-Matos, L., Afsarmanesh, H., Kaletas, E. C., and Cardoso, T. "Service Federation in Virtual Organizations." presented at 11th International PROLAMAT Conference on Digital Enterprise New Challenges, Budapest, Hungary, 305-324, 2001.

5. Camarinha-Matos, L. M. "Virtual Enterprises teaching at UNL, Portugal." in COVE News - Newsletter on Co-operation infrastructures for Virtual Enterprises and electronic business (6), December, $2003 a$.

6. Camarinha-Matos, L. M., and Afsarmanesh, H., eds. "Infrastructures for Virtual Enteprises Networking Industrial Enterprises.”, Kluwer Academic Publishers, Boston, MA, 512, 1999b.

7. Camarinha-Matos, L. M., and Afsarmanesh, H. "Tendencies and General Requirements for Virtual Enterprises." in Infrastructures for Virtual Enterprises - Networking Industrial Enterprises, L. M. Camarinha-Matos and H. Afsarmanesh, eds., Kluwer Academic, 15-30, 1999c.

8. Camarinha-Matos, L. M., and Afsarmanesh, H. "The Virtual Enterprise Concept." in Infrastructures for Virtual Enterprises - Networking Industrial Enterprises, L. M. Camarinha-Matos and H. Afsarmanesh, eds., Kluwer Academic, 3-14, 1999d.

9. Camarinha-Matos, L. M., and Afsarmanesh, H. "Design of a Virtual Community Infrastructure for Elderly Care." in Collaborative Business Ecosystems and Virtual Enterprises, L. M. CamarinhaMatos, ed., Kluwer Academic Publishers, 439-450, 2002.

10. Camarinha-Matos, L. M., and Afsarmanesh, H., eds. "Processes and Foundations for Virtual Organizations.", Kluwer Academic Publishers, 2003b.

11. Camarinha-Matos, L. M., and Lima, C. P. "Coordination and Configuration Requirements in a Virtual Enterprise." in Infrastructures for Virtual Enterprises - Networking Industrial Enterprises, L. M. Camarinha-Matos and H. Afsarmanesh, eds., Kluwer Academic, 49-64,1999e.

12. Chesbrough, H. W. "When is virtual virtuous?" Harvard Business Review, 74(1), 65-73,1996.

13. Flaig, L. S. "The "Virtual Enterprise": your new model for success." Electronic Business, 153-155, 1992. 
14. Foster, I., Kesselman, C., Nick, J., and Tuecke, S. "The Physiology of the Grid: An Open Grid Services Architecture for Distributed Systems Integration.”, http://www.globus.org/research/papers/ogsa.pdf., 2002.

15. Foster, I., Kesselman, C., and Tuecke, S. "The Anatomy of the Grid (to appear)." International Journal of Supercomputer Applications, 2001.

16. Garita, C. "Federated Information Management for Virtual Enterprises," Doctoral Thesis, University of Amsterdam, Amsterdam, The Netherlands, 2001.

17. Garita, C. "Electiva - Organizaciones Virtuales.", http://www.ic-itcr.ac.cr/ cesar/teaching/VO-I-03/, 2003a.

18. Garita, C., Afsarmanesh, H., and Hertzberger, L. O. "A Survey of Distributed Information Management Approaches for Virtual Enterprise Infrastructures.” in Managing Virtual Web Organizations in the 21st Century: Issues and Challenges, U. J. Franke, ed., Idea Group Publishing, 164-183, 2002a.

19. Garita, C., Kaletas, E. C., Afsarmanesh, H., and Hertzberger, L. O. "A Service Interface Definitions Catalogue for Virtual Enterprises in Tourism." presented at 5th IFIP International Conference on Information Technology for Balanced Automation Systems - BASYS'2002, Cancun, Mexico, $97-$ 108, 2002b.

20. Garita, C., Unal, O., Afsarmanesh, H., and Hertzberger, L. O. "Building a Virtual Laboratory for Scientific Experimentation in Molecular Biology." in Processes and Foundations for Virtual Organizations, L. M. Camarinha-Matos and H. Afsarmanesh, eds., Kluwer Academic, 181-190, 2003 b.

21. Globus. "The Globus Project.", www.globus.org, 2002.

22. Goranson, H. T. The Agile Virtual Enterprise: Cases, Metrics, Tools: Greenwood Publishing Group, 1999.

23. Goranson, H. T. "Some Insights Toward a Graduate Program in USA." in COVE News - Newsletter on Co-operation infrastructures for Virtual Enterprises and electronic business (6), December, 2003.

24. Osorio, L., Barata, M., and Gibon, P. "Communication Infrastructure Requirements in a VE." in Infrastructures for Virtual Enterprises - Networking Industrial Enterprises, L. M. Camarinha-Matos and H. Afsarmanesh, eds., Kluwer Academic, 65-76,1999.

25. Rabelo, R. "Education and Training in VE/VO at UFSC - Brazil." in COVE News - Newsletter on Cooperation infrastructuresfor Virtual Enterprises and electronic business (6), December, 2003.

26. Sheth, A., and Larson, J. "Federated Database Systems for Managing Distributed, Heterogeneous, and Autonomous Databases." ACM Computing Surveys, 22(3), 183-236, 1990.

27. THINKcreative. "ThinkCreative - Thinking network of experts on emerging smart organizations.", http://www.thinkcreative.org/, 2002.

28. VOmap. "VOmap Project.", http://cic.vtt.fi/projects/vomap/, 2002.

29. WFMC. "The Workflow Reference Model." TCOO -103, Issue 1.1, Workflow Management Coalition, Brussels, 1994. 